\title{
Chapter 19 Signaling Pathways of SARS-CoV In Vitro and In Vivo
}

\author{
Tetsuya Mizutani
}

\begin{abstract}
Severe acute respiratory syndrome (SARS) is a respiratory illness with variable symptoms that was recognized as the first near-pandemic infectious disease of the twenty-first century. A novel human coronavirus, named SARS coronavirus (SARS-CoV), derived from SARS patients was reported as the etiologic agent of SARS. Studying the signaling pathways of SARS-infected cells is key to understanding the molecular mechanism of SARS viral infection. Cell death is observed in cultured Vero E6 cells after SARS-CoV infection. From SARS-CoV infection to cell death, p38 mitogen-activated protein kinase (MAPK) is a key participant in the determination of cell death and survival. Two signaling pathways comprising signal transducer and activator of transcription 3 (STAT3) and p90 ribosomal S6 kinase (p90RSK) are downstream of p38 MAPK. AKT and JNK (Jun $\mathrm{NH}_{2}$-terminal kinase) signaling pathways are important to establish persistent infection of SARS-CoV in Vero E6 cells. Expression studies of SARS-CoV proteins indicate that the viral proteins are able to activate signaling pathways of host cells. The study of signaling pathways in SARS-CoV patients is difficult to perform compared with in vitro studies due to the effects of the human immune system. This review highlights recent progress in characterizing signal transduction pathways in SARS-CoV-infected cells in vitro and in vivo.
\end{abstract}

\subsection{Introduction}

Severe acute respiratory syndrome (SARS) is a respiratory illness with variable flulike symptoms and pneumonia, which is caused by the SARS coronavirus (SARSCoV) (Drosten et al. 2003; Ksiazek et al. 2003; Peiris et al. 2003a, 2003b; Poutanen

\footnotetext{
T. Mizutani

Department of Virology I, National Institute of Infectious Diseases, Gakuen 4-7-1, Musashimurayama, Tokyo208-0011, Japan

e-mail: tmizutan@nih.go.jp
} 
et al. 2003; Tsang et al. 2003). SARS was first recognized in China in November 2002 and subsequently spread to 29 other countries, thus emerging as the first nearpandemic infectious disease of the twenty-first century. A worldwide total of 8,096 cases of SARS, of which $774(9.6 \%)$ resulted in death, was reported by the World Health Organization (WHO) (http://www.who.int/csr/sars/country/table2004_04_ 21/en/index.html).

SARS-CoV belongs to the Coronaviridae family (order Nidovirales) of enveloped single-stranded positive RNA viruses (Marra et al. 2003; Rota et al. 2003; Thiel et al. 2003). The SARS-CoV genome is approximately $30 \mathrm{~kb}$ in length and is the longest known amongst the RNA virus genomes. The SARS-CoV genomic RNA has a cap structure and a poly-A tail at the $5^{\prime}$ and $3^{\prime}$ ends, respectively. SARS$\mathrm{CoV}$ genome replication occurs in the cytoplasm. During viral replication, a full-length genomic negative-stranded RNA is transcribed from genomic positivestranded RNA by the viral RNA polymerase that is initially translated from genomic RNA. Approximately $60 \%$ of SARS-CoV genomic RNA encodes viral polymerase and its related proteins. The mRNA transcription of coronavirus is unique, because all mRNAs have a nested set structure. The mRNAs have a $5^{\prime}$ leader sequence of approximately 70 nucleotides and poly-A tails at the $3^{\prime}$ end. Mouse hepatitis virus (MHV), which is a prototype of coronavirus, has seven mRNAs, whereas SARS-CoV has at least nine mRNAs. The leader RNA is transcribed from the $3^{\prime}$ end of full-length genomic negative-stranded RNA. There is strong evidence that the leader RNA is transcribed as small sized-RNA, which is approximately 70 bases in length. The leader RNA binds to intragenic initiation sites on negative-stranded RNA, and then viral RNA polymerase starts to transcribe mRNA at the site. The SARS-CoV viral genomic RNA comprises 14 open reading frames (ORFs), and eight of the encoded proteins are unique compared with other coronaviruses. These unique proteins are thought to be involved in the pathogenetic mechanism of SARS-CoV.

Large overlapping polyproteins ( $1 \mathrm{a}$ and $1 \mathrm{~b}$ ) encoded by approximately $60 \%$ of the SARS-CoV viral genome are processed into 16 nonstructural proteins including polymerase and proteases (chymotrypsin-like cysteine protease and papain-like protease). These proteins are thought to be essential in viral replication and transcription. The viral particle of SARS-CoV mainly consists of four structural proteins, spike (S), membrane (M), envelope (E), and nucleocapsid (N) (Fig. 19.1). The viral particle may also comprise viral accessory proteins that bind to the structural proteins. The S protein binds to the viral receptor of host cells and enables the virus to enter the cytoplasm by endocytosis.

SARS-CoV has the potential to cause respiratory illness in human patients. Cytokine storm occurs in SARS-CoV-infected patients and is one of the observed pathologic mechanisms of SARS-CoV infection. On the other hand, apoptotic cell death is observed in vitro when SARS-CoV-sensitive cultured cells such as Vero E6 cells are used (Mizutani et al. 2004c). Various signaling pathways are activated during the entire process of viral infection, from S protein-ACE2 (Angiotensinconverting enzyme-2) binding for internalization into the host cells to apoptotic cell death (Mizutani 2007). The most common signaling pathways are mitogen-activated 


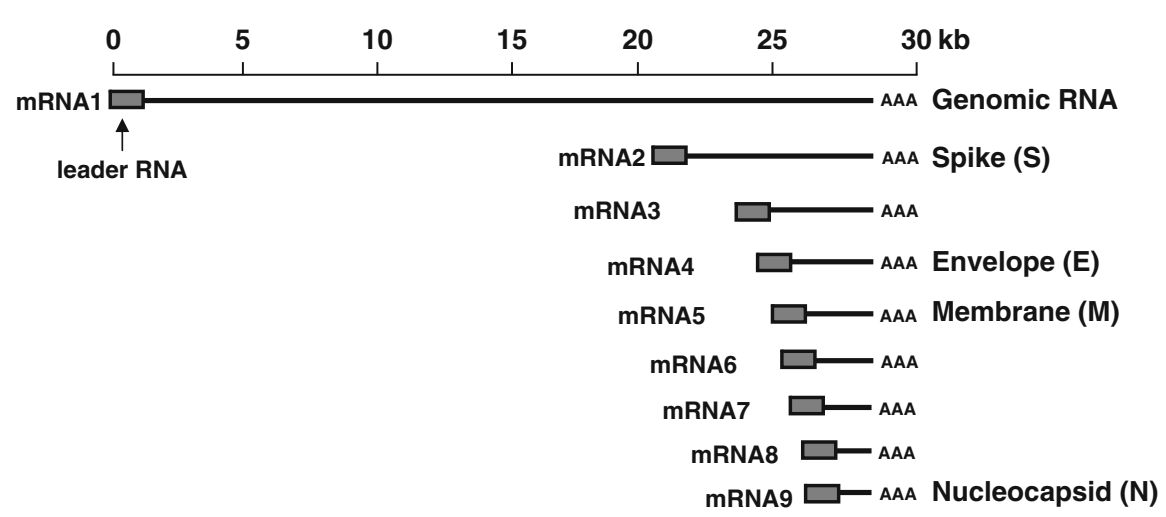

Fig. 19.1 SARS-CoV mRNAs in infected cells. Structural proteins are indicated

protein kinase (MAPK) pathways, which include Jun $\mathrm{NH}_{2}$-terminal kinase (JNK), extracellular signal-regulated kinase (ERK), and p38 MAPK. These three major MAPKs are highly conserved in a wide range of species from yeast to mammals and are regulatory proteins of cell death and cell survival in living cells. Thus, MAPKs are key to the process of apoptosis (Garrington and Johnson 1999). MAPKK kinase (MAPKKK) activates MAPK kinase (MAPKK), and then MAPKK activates MAPK. Generally, the ERK signaling pathway promotes cell survival and proliferation, and JNK and p38 MAPK induce apoptosis. However, the role of each MAPK varies depending on cell type and stimulation. Many signaling pathways are activated in virus-infected cells, and cross-talk activation between signaling pathways occurs. Thus, signaling pathways regulating cell death and survival in virus-infected cells is highly complex.

Analysis of activated signaling pathways in SARS-CoV-infected cells and patients is required for understanding the pathogenesis of SARS. This review highlights recent progress in characterizing signal transduction pathways induced by SARS-CoV infection in vivo and in vitro.

\section{2 p38 MAPK Signaling Pathway in Viral Infection}

The p38 MAP kinase is expressed in response to stressors, and viral infection generally induces activation of p38 MAPK. The roles of p38 MAPK in viral infection/replication have been researched recently as described below.

Environmental stresses, such as UV irradiation, oxidative stimuli and proinflammatory cytokines, are able to induce activation of p38 MAPK. There are at least four isoforms of p38 MAPK: p38 $\alpha$, p38 $\beta$, p38 $\gamma$, and p38 . 1999; Platanias 2003; Lee et al. 2004), but these isoforms are generally not distinguished in the field of virology. However, these four isoforms exhibit different properties and have 
different cellular functions. The $\mathrm{p} 38 \alpha$ and $\mathrm{p} 38 \beta$ MAPKs have more than $70 \%$ similarity at the amino acid sequence level, and their functions are inhibited by the pyridinyl imidazole inhibitor SB203580 [4-(4-fluorophenyl)-2-(4-methylsulfinylphenyl)-5-(4-pyridyl) imidazole]. Conversely, p38 $\gamma$ and p38 $\delta$ MAPKs, which have $60 \%$ similarity to $\mathrm{p} 38 \alpha$, are not inhibited by SB203580. Furthermore, p38 $\alpha$ and $\mathrm{p} 38 \beta$ MAPKs are widely expressed in tissues, whereas the expression of $\mathrm{p} 38 \gamma$ and $\mathrm{p} 38 \delta$ MAPKs is tissue-specific. In the field of virology, because SB203580 is generally used as an inhibitor of the $\mathrm{p} 38$ MAPK signaling pathway, it can be used in studying the role of $\mathrm{p} 38 \alpha$ and/or p38 $\beta$ MAPKs in SARS-CoV infection. The kinases upstream of p38 MAPK are MKK3 (MAPK kinase 3) and MKK6 (MAPK kinase 6), which are known to phosphorylate and activate p38 MAPK. Interestingly, MKK6 has affinity to PKR in the presence of double-stranded RNA, poly(rI;rC) and PKR is able to activate MKK6, but not MKK3. This result indicated that interaction of MKK6 and PKR provides a mechanism to regulate activation of p38 MAPK (Silva et al. 2004). In hepatitis C virus-core-expressing cells, PKR has an important role in cell cycle arrest and was shown to interact strongly with p38 MAPK (Spaziani et al. 2006). As upstream of p38MAPK, transforming growth factor (TGF)- $\beta$-activating kinase (TAK1), apoptosis signal-regulatory kinase (ASK1), and MAPKKK4 are known as MAPKKKs.

Downstream targets of p38 MAPK are well-known as mitogen and stressactivated protein kinase 1 (MSK1), MAP kinase-interacting kinase 1 (MNK1), and MAPK-activated protein kinase 2 and 3 (MAPKAPK 2 and 3) (Freshney et al. 1994). These signaling pathway proteins have further downstream targets. For example, MNK1 activates the eukaryotic translation initiation factor $4 \mathrm{E}$ (eIF4E) (Gingras et al. 1999). MAPKAPK2 activates heat shock protein 27 (HSP27), cAMP response element-binding protein (CREB), and transcription factor-1 (ATF-1) (Garrido et al. 2003; Tan et al. 1996). Mouse hepatitis virus (MHV) A59 strain induces interleukin-6 (IL-6) production via eIF4E phosphorylation under p38 MAPK activation (Banerjee et al. 2002). Inhibitors of p38 MAPK inhibit transcription of viral mRNA and production of viral protein, indicating that $\mathrm{p} 38$ MAPK is utilized to promote viral protein synthesis. Conversely, p38 MAPK enhances transcription of CHOP (C/EBP homologous protein) encoded by the growth arrest- and DNA damage-inducible gene 153 (GADD153) (Wang et al. 1996). The p38 MAPK-induced apoptosis via activation of the CHOP pathway occurs in cells infected with Japanese encephalitis virus (JEV) (Su et al. 2002). The H5N1 subtype of influenza virus induces tumor necrosis factor alpha (TNF- $\alpha$ ) expression via activation of p38 MAPK (Lee et al. 2005). The p38 MAPK signaling pathway is thought to primarily induce apoptosis in virus-infected cells. As described in HCV infection, p38 MAPK is able to promote cell survival. Although p38 MAPK is activated in many cases of viral infection, viral proteins sometimes negatively regulate p38 MAPK. The ORF 61 protein of varicella-zoster virus (VZV) is known to repress phosphorylation of p38 MAPK for negative regulation of cellular proinflammatory responses (Rahaus et al. 2005). Thus, activation or inactivation of p38 MAPK occurs in the pathogenesis of disease caused by viral infection. 


\section{3 p38 MAPK Signaling Pathway in SARS-CoV-Infected Cells}

The p38 MAPK signaling pathway takes part in cell death, as previously described. Apoptosis is an active and physiologic type of cell death and is a host cell's protective mechanism for preventing the spread of viral particles before production of viral particles. Vero and Vero E6 cells, which are monkey kidney cells, are widely used in SARS-CoV research because of their high susceptibilities to infection due to lack of interferon genes. Apoptosis has been shown to be inducible by infection with SARS-CoV (Mizutani et al. 2004c; Yan et al. 2004). Cytopathic effects (CPEs), defined as focal cell rounding and DNA fragmentation typical of apoptosis, are observed in SARS-CoV-infected Vero E6 cells at $24 \mathrm{~h}$ post-infection (h.p.i.) (Mizutani et al. 2004c). Activated caspase 3, which has an essential role in apoptosis, was detected at peak levels at 24 h.p.i. On the other hand, the phosphorylation level of p38 MAPK reached a maximum at 18 h.p.i. in virus-infected cells. The phosphorylated p38 MAPK was active, as shown by using an in vitro kinase assay. The CPE observed in SARS-CoV-infected cells is slightly inhibited by SB203580, and therefore p38 MAPK activation is thought to induce CPE of virus-infected cells. However, DNA fragmentation is not inhibited by the inhibitor. Apoptosis and CPE are thought to be linked, and activation of p38 MAPK is a promoter of cell death in Vero E6 cells infected by SARS-CoV. However, SB203580 treatment of Vero E6 cells indicates that there is no requirement for p38 MAPK activation in SARS-CoV replication. The p38 MAPK signaling pathway perhaps has other roles in SARS-CoV-infected cells.

The downstream targets of p38 MAPK are phosphorylated in SARS-CoVinfected cells. The level of phosphorylated eIF4E is increased in SARS-CoVinfected cells (Mizutani et al. 2004c). However, the activated eIF4E does not regulate viral protein synthesis, as demonstrated by the similar kinetics of viral protein accumulation in infected Vero E6 cells in the presence and absence of SB203580. Both MAPKAPK-2 and its substrate HSP-27 are phosphorylated in virus-infected cells. HSP-27 is known as an anti-apoptotic protein as it inhibits apoptosome formation (Garrido et al. 2003). CREB is also known to mediate a survival signal under various conditions (Tan et al. 1996; Ginty et al 1994; von Knethen et al. 1998), and CREB is also phosphorylated in SARS-CoV-infected cells. The expression of SARS-N protein in transfected COS-1 cells induces phosphorylation of p38 MAPK, HSP-27, and CREB (Surjit et al. 2004), whereas the viral-N protein expression system of vaccinia virus (DIs-N) does not induce phosphorylation of p38 MAPK (Mizutani et al. 2006d). Activation of the p38 MAPK pathway induces actin reorganization in COS-1 cells devoid of growth factors (Surjit et al. 2004). Furthermore, the 7a protein of SARS-CoV induces apoptotic cell death and phosphorylation of p38 MAPK in 293 T cells (KopeckyBromberg et al. 2006). However, SB203580 does not prevent cell rounding, apoptosis, and chromatin condensation induced by the 7 a protein. The differences in the results are most likely due to the use of different cell cultures and expression 
systems. Overall, phosphorylated proteins downstream of p38 MAPK have the potential to induce an anti-apoptotic environment in SARS-CoV-infected cells. However, activated p38 MAPK in SARS-CoV-infected cells is thought to be able to promote both cell death and survival. Perhaps there are other substrates of $\mathrm{p} 38$ MAPK that are inducible on cell death of Vero E6 cells caused by SARS-CoV infection, or perhaps there is cross-talk between the p38 MAPK signaling pathway and other signaling pathways inducing cell death.

\subsection{Downstream Signaling Pathways of p38 MAPK}

In Vero E6 cells, signal transducer and activator of transcription (STAT) 3 protein is constitutively phosphorylated at Tyr-705 and is slightly phosphorylated at Ser727 (Mizutani et al. 2004a). SARS-CoV infection is able to induce dephosphorylation of STAT3 Tyr-705 after 18 h.p.i. On the other hand, Ser-727-phosphorylated STAT3 is slightly increased at the same point in time. The activity of STAT transcription factors is induced by phosphorylation of a single tyrosine residue, leading to dimerization via an intermolecular SH2 phosphotyrosine interaction (Shuai et al. 1993, 1994; Schindler et al. 1992a, 1992b). STAT3 is known to be activated in response to interleukin-6 (IL-6) and IL-10, and is thought to act as an anti-apoptotic transcription factor (Rajan and Mckay 1998; Grandis et al. 2000; Mora et al. 2002). Tyr-705 phosphorylation of STAT is necessary for its activation (Shuai et al. 1993, 1994; Schindler et al. 1992b), suggesting that SARS-CoV infection leads to a decrease in STAT3 activation. Furthermore, STAT3 does not act as a transcriptional enhancer in SARS-CoV-infected Vero E6 cells, as shown by the disappearance of Tyr-705-phosphorylated STAT3 from the nuclear fraction post SARS-CoV infection. The proteins upstream of STAT3 in the signaling pathway are Janus kinases (JAK1 and 2) and Tyk2, which are phosphorylated at low levels in mock-infected Vero E6 cells, even after virus infection. The signal transducing adaptor molecule 1 (STAM1), which is known to be associated with Jak2 and Jak3 via the immunoreceptor tyrosine-based activation motif, is upregulated in SARS-CoV-infected Vero E6 cells (Leong et al. 2005). Therefore, Tyr-705 dephosphorylation of STAT3 in virus-infected cells is independent of its upstream kinases, and there may be other signaling pathways regulating STAT3 phosphorylation and dephosphorylation. Two inhibitors of p38 MAPK (SB203580 and SB202190) partially inhibit dephosphorylation of STAT3 at Tyr-705, indicating that the p38 MAPK signaling pathway is upstream of Tyr-705 dephosphorylation of STAT3 in SARS-CoV-infected Vero E6 cells. Inactivation of STAT3 via p38 MAPK activation may induce cell death in SARS-CoV-infected cells. However, the kinetics of STAT3 after SARS-CoV infection varies for different cell types. The suppressors of cytokine signaling-3 (SOCS3) mRNA are suppressed in SARSCoV-infected Caco-2 cells (Okabayashi et al. 2006), leading to continuous activation of STAT3. 
A serine/threonine kinase, p90 ribosomal S6 kinase (RSK), belongs to another signaling pathway, which is regulated by p38 MAPK. Generally, p90RSK is phosphorylated at Thr-573 by ERK (Gavin and Nebreda 1999; Smith et al. 1999), and this phosphorylation induces autophosphorylation at Ser-380, and then PDK1 (phosphoinositide-dependent kinase 1) phosphorylates at Ser-221 (Frödin et al. 2000; Jensen et al. 1999; Richards et al. 1999). No significant differences are observed in phosphorylation levels of p90RSK at Ser-221 and Thr-573 in SARSCoV-infected Vero E6 cells (Mizutani et al. 2006a). However, Ser-380 of p90RSK is phosphorylated in virus-infected confluent cells. Thus, phosphorylation of p90RSK Ser-380 is upregulated without upregulation of Thr-573 in SARS-CoVinfected cells. The phosphorylation of Ser-380 is decreased in SB203580-treated virus-infected cells, indicating that p38 MAPK can induce phosphorylation of Ser380. Furthermore, p90RSK phosphorylates CREB (Frodin and Gammeltoft 1999). In SARS-CoV-infected Vero E6 cells, p38 MAPK activation induces phosphorylation of p90RSK Ser-380, and then CREB is thought to be phosphorylated by activated p90RSK. Thus, p90RSK may have anti-apoptotic activity in SARSCoV-infected cells.

\subsection{ERK1/2 Activation by SARS-CoV Infection}

The SARS-CoV $\mathrm{S}$ protein is able to induce phosphorylation of ERK1/2 in HEK293T cells (Liu et al. 2007). The S-induced protein kinase C (PKC)/ERK signaling pathway promotes nuclear factor-kappa $\mathrm{B}(\mathrm{NF}-\kappa \mathrm{B})$ binding to the cyclooxygenase-2 (COX-2) promoter. Similar results have been reported using the N protein of SARS-CoV (Yan et al. 2006). SARS-CoV S protein expression induces release of interleukin-8 (IL-8) via ERK and p38 MAPK signaling pathways including activator protein 1 (AP-1) in A549 cells (Chang et al. 2004). On the contrary, phosphorylation of ERK1/2 is downregulated in N protein-expressing COS-1 cells in the absence of serum (Surjit et al. 2004). Thus, viral proteins can potentially upor downregulate phosphorylation of ERK1/2. ERK1/2 is observed to be phosphorylated in SARS-CoV-infected Vero E6 cells (Mizutani et al. 2004a). After treatment with MAPK/ERK kinase 1 and 2 (MEK1/2)-specific inhibitor (PD98059), SARSCoV-infected Vero E6 cells exhibit no significant changes in activated caspase-3 or caspase-7. Thus, activation of ERK1/2 is not sufficient to prevent cell death by SARS-CoV infection. Furthermore, activation of ERK1/2 is not necessary to establish persistent infection of SARS-CoV in Vero E6 cells (Mizutani et al. 2005).

\subsection{JNK Activation by SARS-CoV}

The SARS-CoV S protein induces CREB binding to COX-2 promoter mediated via the phosphatidylinositol 3-kinase (PI3K)/PKC/JNK pathway in HEK293T cells (Liu et al. 2007). Expression of the SARS-CoV N protein induces phosphorylation 
of JNK in Vero E6 cells (Mizutani et al. 2006d) and in COS-1 cells in the absence of serum (Surjit et al. 2004). The phosphorylation level of Jun, which is dependent upon activation of JNK, also increases in the absence of serum. The SARS-CoV N protein can activate AP-1, which is composed of homodimers and heterodimers of Fos, Jun, CREB, and activating transcription factor (ATF) subunits, in Vero and Huh7 cells (He et al. 2003). The viral accessory proteins, 3a and 7a, phosphorylate JNK1 and JNK3 in HEK293T cells (Kanzawa et al. 2006). Overall, viral proteins are able to induce phosphorylation of JNK in several cell lines. SARS-CoV infection induces phosphorylation of JNK in Vero E6 cells after at least 12 h.p.i. (Mizutani et al. 2004a). The Vero E6 cells begin to show rounding at 24 h.p.i and persistently infected cells are observed after 48 h.p.i (Mizutani et al. 2005). At this time, JNK, Akt, and p38 MAPK are phosphorylated in virus-infected cells. Treatment with an inhibitor of JNK (SP600125), and PI3K (LY294002), inhibits the establishment of persistence, whereas treatment with an inhibitor of MEK1/ 2 (PD98059) and p38 MAPK (SB203580) does not inhibit persistence of infection (Mizutani et al. 2005). Thus, two different signaling pathways of JNK and PI3K/ Akt are important for the establishment of persistently infected Vero E6 cells (Mizutani et al. 2006d, 2007).

\subsection{PI3K/Akt Activation by SARS-CoV}

Akt, which is also known as protein kinase B (PKB), is phosphorylated at both Ser473 and Thr-308 residues via the PI3K signaling pathway upon stimulation by growth factors, insulin, and hormones (Toker 2000; Brazil and Hemmings 2001; Scheid and Woodgett 2003; Welch et al. 1998). The main role of Akt is inhibition of apoptosis via phosphorylation of the forkhead transcription factor (FKHR) family, glycogen synthase kinase-3 $\beta$ (GSK-3 $\beta$ ), caspase-9, and Bcl-associated death protein (Bad) (Cardone et al. 1998; Cross et al. 1995; Datta et al. 1997). Interestingly, GSK-3 regulates phosphorylation of $\mathrm{N}$ protein (Wu et al. 2009). The M protein of SARS-CoV induces apoptosis in both HEK293T cells and transgenic Drosophila (Chan et al. 2007). The M protein-induced apoptosis involves mitochondrial release of cytochrome $c$ protein. In SARS-CoV-infected Vero E6 cells, Ser-473 of Akt is phosphorylated at 8 h.p.i. and maximal phosphorylation is observed at 18 h.p.i. (Mizutani et al. 2004b), after which Akt is dephosphorylated. Thr-308 phosphorylation has not been detected in Vero E6 cells. The phosphorylation of Ser-473 of Akt by viral infection is inhibited by LY294002, which is an inhibitor of the PI3K signaling pathway. An in vitro kinase activity assay of Akt in SARS-CoV-infected cells indicated that Akt is highly phosphorylated only at serine residues, but Akt activity is low. Therefore, weak activation of Akt cannot prevent apoptosis induced by SARS-CoV infection in Vero E6 cells. The phosphorylation of Akt in virusinfected cells is necessary to establish persistence, but Akt is not phosphorylated after establishing persistent cell lines (Mizutani et al. 2005, 2006d), suggesting that activation of PI3K/Akt is essential for the establishment of persistent infection with 
SARS-CoV at points in time before cell death. The above characterizations of Akt in SARS-CoV-infected Vero E6 cells are mainly derived from experiments using confluent cells. When subconfluent Vero E6 cells are infected by SARS-CoV, cell proliferation is inhibited (Mizutani et al. 2006c). SARS-CoV infection induces dephosphorylation of a serine residue of Akt without phosphorylation in subconfluent cultures. Thus, downregulation of Akt activity in SARS-CoV-infected cells prevents cell proliferation.

\subsection{NF-кB Activation and Inhibition by SARS-CoV Proteins}

The SARS-CoV N protein is able to activate NF- $\kappa \mathrm{B}$ in Vero E6 cells (Liao et al. 2005). As described above, the $\mathrm{S}$ - and $\mathrm{N}$-induced PKC/ERK signaling pathway promotes NF- $\kappa \mathrm{B}$ binding to the COX-2 promoter (Liu et al. 2007; Yan et al. 2006). SARS-CoV $\mathrm{S}$ and $\mathrm{N}$ proteins may cause inflammation of the lungs by activating $\mathrm{COX}-2$ gene expression. The $3 \mathrm{a}$ and $7 \mathrm{a}$ viral accessory proteins enhance $\mathrm{NF}-\kappa \mathrm{B}$ mediated transcription in HEK293T cells (Kanzawa et al. 2006). In contrast, the $\mathrm{N}$ protein inhibits interferon production in $293 \mathrm{~T}$ cells via inhibition of $\mathrm{NF}-\kappa \mathrm{B}$ (Kopecky-Bromberg et al. 2007). The M protein also suppresses NF- $\kappa \mathrm{B}$ activity (Fang et al. 2007). Growth arrest and apoptosis via caspase-3 and caspase-9 activities are induced in SARS-CoV $3 \mathrm{C}$-like protease $\left(3 \mathrm{CL}^{\text {pro }}\right)$-expressing human promonocyte HL-CZ cell line (Lin et al. 2006). The SARS-CoV 3CL ${ }^{\text {pro }}$ may increase activation of $\mathrm{NF}-\kappa \mathrm{B}$ and upregulate cytochrome $c$ oxidase and downregulate Hsp-70, inducing mitochondrial-mediated apoptosis (Lai et al. 2007). Viral papain-like protease (PLP) regulates antagonism of IRF3 and NF- $\kappa \mathrm{B}$ signaling pathways (Frieman et al. 2009).

\subsection{Inhibitory Effects of Viral Proteins on the Cell Cycle}

The 3a protein of SARS-CoV has the potential to inhibit cell cycle progression at the $\mathrm{G}_{1}$ phase in HEK293, COS-7, and Vero cells (Yuan et al. 2005, 2007). The C-terminal region of the 3 a protein, which includes a potential ATPase motif, is essential to inhibit the cell cycle. The 3a protein expression reduces cyclin D3 level and inhibits retinoblastoma $(\mathrm{Rb})$ phosphorylation. The p53 phosphorylation is increased by $3 \mathrm{a}$ expression. The $7 \mathrm{a}$ protein expression also blocks cell cycle progression at the $\mathrm{G}_{0} / \mathrm{G}_{1}$ phase in HEK293, COS-7, and Vero cells by mechanisms similar to those of the 3 a protein (Yuan et al. 2006). The $\mathrm{N}$ protein is a substrate of cyclin-dependent kinase (CDK) as well as GSK, MAPK, and casein kinase II (Surjit et al. 2005). The $\mathrm{N}$ protein directly binds to cyclin $\mathrm{D}$ and inhibits activity of the cyclin D-CDK4 complex. The $\mathrm{N}$ protein also inhibits CDK2 activity by direct binding to the CDK2-cyclin complex, resulting in blocking the $\mathrm{S}$ phase progression 
in COS-7 and Huh7 cells (Surjit et al. 2006). Therefore, proteins of SARS-CoV may have the ability to inhibit the progression of the host cell cycle, but further detailed analysis is required in SARS-CoV-infected cells.

\subsection{Apoptotic Signaling Pathway}

SARS-CoV infection induces apoptotic cell death in Vero E6 cells, via dephosphorylation of STAT3 by p38 MAPK activation, and inactivation of Akt, as previously described. Recent study suggest that SARS-CoV triggers apoptosis via protein kinase R (PKR) (Krähling et al. 2009). Overexpression of SARS-CoV proteins can induce apoptosis in variable cell lines. Induction of apoptosis by various viral proteins may occur at different stages of the infection cycle. SARS$\mathrm{CoV} 3 \mathrm{CL}^{\text {pro }}$ expression in HL-CZ cells induces apoptosis via caspase-3 and caspase-9 (Lin et al. 2006). Furthermore, 3CL ${ }^{\text {pro }}$ expression in HL-CZ cells upregulates proteins located in the mitochondria, but downregulates Hsp-70, which antagonizes apoptosis-inducing factor (Lai et al. 2007). The SARS-CoV 8a protein, localized in the mitochondria of infected cells, increases mitochondrial transmembrane potential, reactive oxygen species production, and caspase- 3 activation, resulting in inducing apoptosis in Vero, HEK293, and Huh7 cells (Chen et al. 2007). ORF 6 induces apoptosis via caspase-3 mediated, ER stress and JNKdependent pathways (Ye et al. 2008). SARS-CoV N protein modulates the TGF- $\beta$ signaling pathway to block apoptosis of SARS-CoV-infected host cells (Zhao et al. 2008). In the absence of serum, the SARS-CoV N protein can induce apoptosis by activating the mitochondrial pathway (Zhang et al. 2007), and/or by downregulating ERK and Akt signaling pathways (Surjit et al. 2004) in COS-1 cells, but not in Hep-G2 and Huh-7 cells (Zhang et al. 2007). The SARS-CoV S protein and its C-terminal domain (S2) induce apoptosis in Vero E6 cells, but the S1, E, M, and N proteins are not able to induce apoptosis in Vero E6 cells (Chow et al. 2005). In contrast, the SARS-CoV M and N proteins can induce apoptosis in human pulmonary fibroblast (HPF) cells (Zhao et al. 2006). The M protein induces apoptosis through modulation of the Akt pathway and mitochondrial cytochrome $c$ release in HEK293T cells and transgenic Drosophila [85]. Overexpression of SARS-CoV 3a protein in Vero E6 cells induces apoptosis, mediated through a caspase-8-dependent pathway or p38 MAPK (Law et al. 2005; Waye et al. 2005; Padhan et al. 2008). The 3a protein expression in Drosophila induces apoptosis, which could be modulated by cellular cytochrome $c$ levels and caspase activity (Wong et al. 2005). The SARS-CoV $3 b$ protein induces both necrosis and apoptosis in Vero E6 cells (Khan et al. 2006). The SARS-CoV 7a protein interacts with pro-survival proteins, basal cell lymphoma-extra large (Bcl-xL), B cell lymphoma 2 (Bcl-2), Bcl-w, A1, and myeloid cell leukaemia sequence 1 (Mcl-1), at the endoplasmic reticulum and the mitochondria, resulting in triggering apoptosis in HEK293T and Vero E6 cells (Tan et al. 2007). Interestingly, the 7 a protein does not interact with the pro-apoptotic members, Bcl-2 associated X protein (Bax), Bcl-2 homologous killer (Bak), Bad, 
and Bcl-2 interacting domain (Bid). However, a mutant virus without the $7 \mathrm{a} / 7 \mathrm{~b}$ gene is able to induce extensive CPEs in the Vero cell line (Yount et al. 2005), suggesting that the 7 a protein is not a dominant contributor to virus-induced cell death in this cell culture system. The SARS-CoV N protein downregulates the level of Bcl-2 in COS-1 cells (Surjit et al. 2004). The SARS-CoV E protein induces apoptosis in Jurkat $\mathrm{T}$ cells in the absence of growth factors, but apoptosis is inhibited by overexpression of Bcl-xL via interaction with the E protein (Yang et al. 2005). Apoptosis is also inhibited by overexpression of Bcl-2 in SARS-CoVinfected Vero cells (Bordi et al. 2006). In the virus-infected Vero cells, downregulation of Bcl-2 and upregulation of Bax are observed (Ren et al. 2005). Bcl-xL activation plays important roles in establishing persistent infection of SARSCoV (Mizutani et al. 2006b). The N protein upregulates the Bcl-xL protein level (Mizutani et al. 2006d). These reports indicate that Bcl-xL activation is the key to preventing apoptosis due to SARS-CoV infection. The other viral proteins localized in the mitochondria of infected cells may also interact with Bcl-xL and other prosurvival proteins.

\subsection{Signaling Pathways in SARS Patients}

Western blots are used to analyze signaling pathway proteins of cultured cells infected with SARS-CoV or transfected with plasmids encoding viral proteins. Thus, the kinetics of phosphor-proteins regulating signaling pathways is important for understanding which signaling pathways are activated in virus-infected cells. However, in vivo analysis and amounts of mRNA from whole blood or tissues of SARS patients are primarily analyzed using DNA microarrays. Unfortunately, when the level of mRNA related to a signaling pathway increases in SARS patients, as measured by DNA microarray analysis, the results do not suggest activation of particular signaling pathways, due to the analysis being performed on a mixed population of cells. The roles of signaling pathways may be different amongst different cell types. Analyses of signaling pathways in virus-infected patients are still difficult to perform for these reasons. However, flow cytometric analysis of cell samples from virus-infected patients provides an improved method for the investigation of signaling pathways in vivo. Flow cytometric analysis of phospho-p38 indicated that augmented p38 MAPK phosphorylation of CD14 monocytes was associated with suppressed p38 MAPK phosphorylation of CD8 lymphocytes, suggesting that altered leukocyte p38 activation contributes to abnormal blood cytokine profiles in SARS patients (Lee et al. 2004).

Analysis of cell apoptosis in SARS patients is key to understanding the signaling pathways that regulate apoptosis. In SARS patients, lymphopenia caused by depletion of T lymphocytes by apoptosis is a common abnormality (Chen et al. 2006). Compared to healthy controls, SARS patients have significantly lower lymphocyte and platelet counts and have significantly higher vascular cell adhesion molecule-1 (sVCAM-1) levels and soluble Fas ligand (sFasL) levels, as determined using 
ELISA (enzyme-linked immunosorbent assay). SARS patients also have intracellular activated caspase- 3 fragment levels, as measured using flow cytometry (Peiris et al. 2003b). Liver impairment commonly occurs amongst patients with SARS, indicating that SARS-CoV may be localized in the liver (Chau et al. 2004). The pathologic features, perhaps due to apoptosis, are the presence of acidophilic bodies, ballooning of hepatocytes, and mild to moderate lobular activities. The thyroid glands of SARS-infected patients show extensive injury due to apoptosis of the follicular epithelial cells and the parafollicular cells, as measured using terminal deoxynucleotidyl transferase-mediated dUTP nick end-labeling assay (Wei et al. 2007). Necrosis is also observed in splenic lymphoid tissue and lymph nodes of SARS patients (Ding et al. 2003). MyD88-mediated innate immune signaling and inflammatory cell recruitment to the lung in BALB/c mice may be required for protection from lethal recombinant mouse-adapted SARS-CoV infection (Sheahan et al. 2008). Further detailed analysis of apoptosis in cells of SARS patients is required, but the initial reports indicate the activation of apoptotic signaling pathways in SARS patients.

\subsection{Conclusion}

Both pro-apoptotic and pro-survival signaling pathways are activated in SARSCoV-infected cells (Fig. 19.2). The balance of activities of signaling pathways is important for determination of cell death or cell survival. In SARS patients, analysis of signaling pathways is further complicated because many cell types respond to viral infection. For example, immune cells infected by SARS-CoV produce and release cytokines, and the cytokines activate other cells. Thus, in SARS patients, many types of cells are infected by SARS-CoV, compared with one type of cell used for in vitro experiments. In addition, the viral proteins that interact with cellular proteins in signaling pathways must be further clarified to understand the

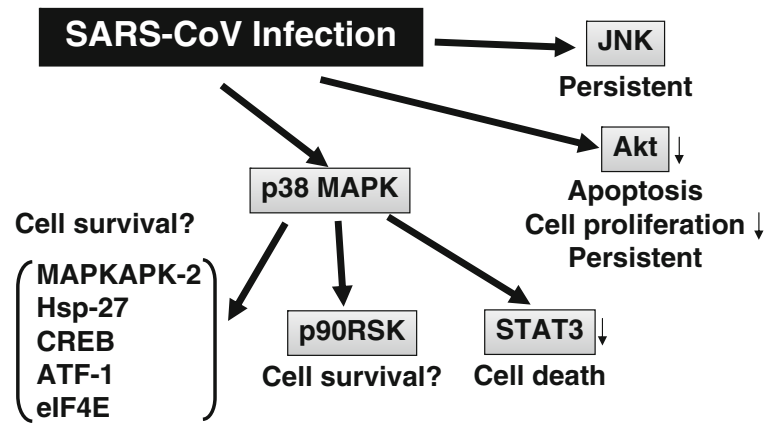

Fig. 19.2 Signaling pathways in cells infected with SARS-CoV. Because each report in this chapter used different cultured cells, this figure is shown based on our experiments using Vero E6 cells 
molecular mechanisms of SARS-CoV infection. It is particularly important to determine the viral proteins that are necessary and sufficient to fully activate signaling pathways leading to apoptotic cell death. Determining the SARS-CoVinduced signaling pathways in SARS patients will enable the development of therapeutic reagents that can inhibit the pathways of apoptotic cell death and production of cytokines.

Acknowledgments I am grateful to Drs. Shuetsu Fukushi, Masayuki Saijo, Momoko Ogata, Kouji Sakai, Ichiro Kurane, and Shigeru Morikawa (National Institute of Infectious Diseases) for their comments on this manuscript. This work was supported, in part, by a grant-in-aid from the Ministry of Health, Labor, and Welfare of Japan and Japan Society for the Promotion of Science.

\section{References}

Banerjee S, Narayanan K, Mizutani T, Makino S (2002) Murine coronavirus replication-induced p38 mitogen-activated protein kinase activation promotes interleukin-6 production and virus replication in cultured cells. J Virol 76:5937-5948

Bonni A, Brunet A, West AE, Datta SR, Takasu MA, Greenberg ME (1999) Cell survival promoted by the Ras-MAPK signaling pathway by transcription-dependent and -independent mechanisms. Science 286:1358-1362

Bordi L, Castilletti C, Falasca L, Ciccosanti F, Calcaterra S, Rozera G, Di Caro A, Zaniratti S, Rinaldi A, Ippolito G, Piacentini M, Capobianchi MR (2006) Bcl-2 inhibits the caspasedependent apoptosis induced by SARS-CoV without affecting virus replication kinetics. Arch Virol 151:369-377

Brazil DP, Hemmings BA (2001) Ten years of protein kinase B signalling: a hard Akt to follow. Trends Biochem Sci 26:657-664

Cardone MH, Roy N, Stennicke HR, Salvesen GS, Franke TF, Stanbridge E, Frisch S, Reed JC (1998) Regulation of cell death protease caspase-9 by phosphorylation. Science 282:1318 1321

Chan CM, Ma CW, Chan WY, Chan HY (2007) The SARS-Coronavirus Membrane protein induces apoptosis through modulating the Akt survival pathway. Arch Biochem Biophys 459 (2): 197-207

Chang YJ, Liu CY, Chiang BL, Chao YC, Chen CC (2004) Induction of IL-8 release in lung cells via activator protein-1 by recombinant baculovirus displaying severe acute respiratory syndrome-coronavirus spike proteins: identification of two functional regions. J Immunol 173:7602-7614

Chau TN, Lee KC, Yao H, Tsang TY, Chow TC, Yeung YC, Choi KW, Tso YK, Lau T, Lai ST, Lai CL (2004) SARS-associated viral hepatitis caused by a novel coronavirus: report of three cases. Hepatology 39:302-310

Chen RF, Chang JC, Yeh WT, Lee CH, Liu JW, Eng HL, Yang KD (2006) Role of vascular cell adhesion molecules and leukocyte apoptosis in the lymphopenia and thrombocytopenia of patients with severe acute respiratory syndrome (SARS). Microbes Infect 8:122-127

Chen CY, Ping YH, Lee HC, Chen KH, Lee YM, Chan YJ, Lien TC, Jap TS, Lin CH, Kao LS, Chen YM (2007) Open reading frame 8a of the human severe acute respiratory syndrome coronavirus not only promotes viral replication but also induces apoptosis. J Infect Dis 196:405-415

Chow KY, Yeung YS, Hon CC, Zeng F, Law KM, Leung FC (2005) Adenovirus-mediated expression of the C-terminal domain of SARS-CoV spike protein is sufficient to induce apoptosis in Vero E6 cells. FEBS Lett 579:6699-6704 
Cross DA, Alessi DR, Cohen P, Andjelkovich M, Hemmings BA (1995) Inhibition of glycogen synthase kinase-3 by insulin mediated by protein kinase B. Nature 378:785-789

Datta SR, Dudek H, Tao X, Masters S, Fu H, Gotoh Y, Greenberg ME (1997) Akt phosphorylation of BAD couples survival signals to the cell-intrinsic death machinery. Cell 91:231-241

Ding Y, Wang H, Shen H, Li Z, Geng J, Han H, Cai J, Li X, Kang W, Weng D, Lu Y, Wu D, He L, Yao K (2003) The clinical pathology of severe acute respiratory syndrome (SARS): a report from China. J Pathol 200:282-289

Drosten C, Gunther S, Preiser W, van der Werf S, Brodt HR, Becker S, Rabenau H, Panning M, Kolesnikova L, Fouchier RA et al (2003) Identification of a novel coronavirus in patients with severe acute respiratory syndrome. N Engl J Med 348:1967-1976

Fang X, Gao J, Zheng H, Li B, Kong L, Zhang Y, Wang W, Zeng Y, Ye L (2007) The membrane protein of SARS-CoV suppresses NF-kappaB activation. J Med Virol 79:1431-1439

Freshney NW, Rawlinson L, Guesdon F, Jones E, Cowley S, Hsuan J, Saklatvala J (1994) Interleukin-1 activates a novel protein kinase cascade that results in the phosphorylation of Hsp27. Cell 78:1039-1049

Frieman M, Ratia K, Johnston RE, Mescar AD, Baric RS (2009) SARS Coronavirus papain-like protease ubiquitin-like domain and catalytic domain regulate antagonism of IRF3 and NFkB signaling. J Virol 83:6689-6705

Frodin M, Gammeltoft S (1999) Role and regulation of $90 \mathrm{kDa}$ ribosomal S6 kinase (RSK) in signal transduction. Mol Cell Endocrinol 151:65-77

Frödin M, Jensen CJ, Merienne K, Gammeltoft S (2000) A phosphoserine-regulated docking site in the protein kinase RSK2 that recruits and activates PDK1. EMBO J 19:2924-2934

Garrido C, Schmitt E, Candé C, Vahsen N, Parcellier A, Kroemer G (2003) HSP27 and HSP70: potentially oncogenic apoptosis inhibitors. Cell Cycle 2:579-584

Garrington TP, Johnson GL (1999) Organization and regulation of mitogen-activated protein kinase signaling pathways. Curr Opin Cell Biol 11:211-218

Gavin AC, Nebreda AR (1999) A MAP kinase docking site is required for phosphorylation and activation of p90rsk/MAPKAP kinase-1. Curr Biol 9:281-284

Gingras AC, Raught B, Sonenberg N (1999) eIF4 initiation factors: effectors of mRNA recruitment to ribosomes and regulators of translation. Annu Rev Biochem 68:913-963

Ginty DD, Bonni A, Greenberg ME (1994) Nerve growth factor activates a Ras-dependent protein kinase that stimulates c-fos transcription via phosphorylation of CREB. Cell 77:713-725

Grandis JR, Drenning SD, Zeng Q, Watkins SC, Melhem MF, Endo S, Johnson DE, Huang L, He Y, Kim JD (2000) Constitutive activation of Stat3 signaling abrogates apoptosis in squamous cell carcinogenesis in vivo. Proc Natl Acad Sci U S A 97:4227-4232

He R, Leeson A, Andonov A, Li Y, Bastien N, Cao J, Osiowy C, Dobie F, Cutts T, Ballantine M, Li X (2003) Activation of AP-1 signal transduction pathway by SARS coronavirus nucleocapsid protein. Biochem Biophys Res Commun 311:870-876

Jensen CJ, Buch MB, Krag TO, Hemmings BA, Gammeltoft S, Frodin M (1999) 90-kDa ribosomal S6 kinase is phosphorylated and activated by 3-phosphoinositide-dependent protein kinase-1. J Biol Chem 274:27168-27176

Kanzawa N, Nishigaki K, Hayashi T, Ishii Y, Furukawa S, Niiro A, Yasui F, Kohara M, Morita K, Matsushima K, Le MQ, Masuda T, Kannagi M (2006) Augmentation of chemokine production by severe acute respiratory syndrome coronavirus $3 \mathrm{a} / \mathrm{X} 1$ and $7 \mathrm{a} / \mathrm{X} 4$ proteins through NF-kappaB activation. FEBS Lett 580:6807-6812

Khan S, Fielding BC, Tan TH, Chou CF, Shen S, Lim SG, Hong W, Tan YJ (2006) Overexpression of severe acute respiratory syndrome coronavirus $3 \mathrm{~b}$ protein induces both apoptosis and necrosis in Vero E6 cells. Virus Res 122:20-27

Kopecky-Bromberg SA, Martinez-Sobrido L, Palese P (2006) 7a Protein of Severe Acute Respiratory Syndrome Coronavirus Inhibits Cellular Protein Synthesis and Activates p38 MitogenActivated Protein Kinase. J Virol 80:785-793

Kopecky-Bromberg SA, Martínez-Sobrido L, Frieman M, Baric RA, Palese P (2007) Severe acute respiratory syndrome coronavirus open reading frame (ORF) 3b, ORF 6, and nucleocapsid proteins function as interferon antagonists. J Virol 81:548-557 
Krähling V, Stein DA, Spiegel M, Weber F, Mühlberger E (2009) Severe acute respiratory syndrome coronavirus triggers apoptosis via protein kinase $\mathrm{R}$ but is resistant to its antiviral activity. J Virol 83:2298-2309

Ksiazek TG, Erdman D, Goldsmith CS, Zaki SR, Peret T, Emery S, Tong S, Urbani C, Comer JA, Lim W et al (2003) A novel coronavirus associated with severe acute respiratory syndrome. N Engl J Med 348:1953-1966

Lai CC, Jou MJ, Huang SY, Li SW, Wan L, Tsai FJ, Lin CW (2007) Proteomic analysis of upregulated proteins in human promonocyte cells expressing severe acute respiratory syndrome coronavirus 3C-like protease. Proteomics 7:1446-1460

Law PT, Wong CH, Au TC, Chuck CP, Kong SK, Chan PK, To KF, Lo AW, Chan JY, Suen YK, Chan HY, Fung KP, Waye MM, Sung JJ, Lo YM, Tsui SK (2005) The 3a protein of severe acute respiratory syndrome-associated coronavirus induces apoptosis in Vero E6 cells. J Gen Virol 86:1921-1930

Lee CH, Chen RF, Liu JW, Yeh WT, Chang JC, Liu PM, Eng HL, Lin MC, Yang KD (2004) Altered p38 mitogen-activated protein kinase expression in different leukocytes with increment of immunosuppressive mediators in patients with severe acute respiratory syndrome. J Immunol 172:7841-7847

Lee DC, Cheung CY, Law AH, Mok CK, Peiris M, Lau AS (2005) p38 mitogen-activated protein kinase-dependent hyperinduction of tumor necrosis factor alpha expression in response to Avian Influenza Virus H5N1. J Virol 79:10147-10154

Leong WF, Tan HC, Ooi EE, Koh DR, Chow VT (2005) Microarray and real-time RT-PCR analyses of differential human gene expression patterns induced by severe acute respiratory syndrome (SARS) coronavirus infection of Vero cells. Microbes Infect 7:248-259

Liao QJ, Ye LB, Timani KA, Zeng YC, She YL, Ye L, Wu ZH (2005) Activation of NF-kappaB by the full-length nucleocapsid protein of the SARS coronavirus. Acta Biochim Biophys Sin 37:607-612

Lin CW, Lin KH, Hsieh TH, Shiu SY, Li JY (2006) Severe acute respiratory syndrome coronavirus 3C-like protease-induced apoptosis. FEMS Immunol Med Microbiol 46:375-380

Liu M, Yang Y, Gu C, Yue Y, Wu KK, Wu J, Zhu Y (2007) Spike protein of SARS-CoV stimulates cyclooxygenase-2 expression via both calcium-dependent and calcium-independent protein kinase C pathways. FASEB J 21:1586-1596

Marra MA, Jones SJ, Astell CR, Holt RA, Brooks-Wilson A, Butterfield YS, Khattra J, Asano JK, Barber SA, Chan SY et al (2003) The genome sequence of the SARS-Associated Coronavirus. Science 300:1399-1404

Mizutani T (2007) Emerging infectious diseases. Lai SK (eds) Signal transduction in SARS-CoVinfected cells. Ann N Y Acad Sci 1102:86-95

Mizutani T, Fukushi S, Murakami M, Hirano T, Saijo M, Kurane I, Morikawa S (2004a) Tyrosine dephosphorylation of STAT3 in SARS coronavirus-infected Vero E6 cells. FEBS Lett 577:187-192

Mizutani T, Fukushi S, Saijo M, Kurane I, Morikawa S (2004b) Importance of Akt signaling pathway for apoptosis in SARS-CoV-infected Vero E6 cells. Virology 327:169-174

Mizutani T, Fukushi S, Saijo M, Kurane I, Morikawa S (2004c) Phosphorylation of p38 MAPK and its downstream targets in SARS coronavirus-infected cells. Biochem Biophys Res Commun 319:1228-1234

Mizutani T, Fukushi S, Saijo M, Kurane I, Morikawa S (2005) JNK and PI3K/Akt signaling pathways are required for establishing persistent SARS-CoV infection in Vero E6 cells. Biochim Biophys Acta 1741:4-10

Mizutani T, Fukushi S, Saijo M, Kurane I, Morikawa S (2006a) Regulation of p90RSK phosphorylation by SARS-CoV infection in Vero E6 cells. FEBS Lett 580:1417-1424

Mizutani T, Fukushi S, Saijo M, Kurane I, Morikawa S (2006b) Characterization of persistent SARS-CoV infection in Vero E6 cells. In Perlman S, Holmes K (eds) The Nidoviruses. The control of SARS and other Nidovirus diseases, vol 581. Wiley, New York, pp 323-326 
Mizutani T, Fukushi S, Iizuka D, Inanami O, Kuwabara M, Takashima H, Yanagawa H, Saijo M, Kurane I, Morikawa S (2006c) Inhibition of Cell Proliferation by SARS-CoV infection in Vero E6 cells. FEMS Immunol Med Microbiol 46:236-243

Mizutani T, Fukushi S, Ishii K, Sasaki Y, Kenri T, Saijo M, Kanaji Y, Shirota K, Kurane I, Morikawa S (2006d) Mechanisms of establishment of persistent SARS-CoV-infected cells. Biochem Biophys Res Commun 347:261-265

Mizutani T, Fukushi S, Kenri T, Sasaki Y, Ishii K, Endoh D, Zamoto A, Saijo M, Kurane I, Morikawa S (2007) Enhancement of cytotoxicity against Vero E6 cells persistently infected with SARS-CoV by Mycoplasma fermentans. Arch Virol 152:1019-1025

Mora LB, Buettner R, Seigne J, Diaz J, Ahmad N, Garcia R, Bowman T, Falcone R, Fairclough R, Cantor A, Muro-Cacho C, Livingston S, Karras J, Pow-Sang J, Jove R (2002) Constitutive activation of Stat 3 in human prostate tumors and cell lines: direct inhibition of Stat 3 signaling induces apoptosis of prostate cancer cells. Cancer Res 62:6659-6666

Okabayashi T, Kariwa H, Yokota S, Iki S, Indoh T, Yokosawa N, Takashima I, Tsutsumi H, Fujii $\mathrm{N}$ (2006) Cytokine regulation in SARS coronavirus infection compared to other respiratory virus infections. J Med Virol 78:417-424

Padhan K, Minakshi R, Towheed MA, Jameel S (2008) Severe acute respiratory syndrome coronavirus 3 a protein activates the mitochondrial death pathway through p38 MAP kinase activation. J Gen Virol 89:1960-1969

Peiris JS, Lai ST, Poon LL, Guan Y, Yam LY, Lim W, Nicholls J, Yee WK, Yan WW, Cheung MT, Cheng VC, Chan KH, Tsang DN, Yung RW, Ng TK, Yuen KY, SARS study group (2003a) Coronavirus as a possible cause of severe acute respiratory syndrome. Lancet 361:1319-1325

Peiris JS, Yuen KY, Osterhaus AD, Stohr K (2003b) The severe acute respiratory syndrome. N Engl J Med 349:2431-2441

Platanias LC (2003) p38 mitogen-activated protein kinase pathway and its role in interferon signaling. Pharmacol Ther 98:129-142

Poutanen SM, Low DE, Henry B, Finkelstein S, Rose D, Green K, Tellier R, Draker R, Adachi D, Ayers $\mathrm{M}$ et al (2003) Identification of severe acute respiratory syndrome in Canada. N Engl J Med 348:1995-2005

Rahaus M, Desloges N, Wolff MH (2005) ORF61 Protein of Varicella-Zoster Virus Influences JNK/SAPK and p38/MAPK Phosphorylation. J Med Virol 76:424-433

Rajan P, McKay RD (1998) Multiple routes to astrocytic differentiation in the CNS. J Neurosci $18: 3620-3629$

Ren L, Yang R, Guo L, Qu J, Wang J, Hung T (2005) Apoptosis induced by the SARS-associated coronavirus in Vero cells is replication-dependent and involves caspase. DNA Cell Biol 24:496-502

Richards SA, Fu J, Romanelli A, Shimamura A, Blenis J (1999) Ribosomal S6 kinase 1 (RSK1) activation requires signals dependent on and independent of the MAP kinase ERK. Curr Biol 9:810-820

Rota PA, Oberste MS, Monroe SS, Nix WA, Campagnoli R, Icenogle JP, Peñaranda S, Bankamp B, Maher K, Chen MH et al (2003) Characterization of a novel coronavirus associated with severe acute respiratory syndrome. Science 300:1394-1399

Scheid MP, Woodgett JR (2003) Unravelling the activation mechanisms of protein kinase B/Akt. FEBS Lett 546:108-112

Schindler C, Shuai K, Prezioso VR, Darnell JE Jr (1992a) Activation of transcription by IFNgamma: tyrosine phosphorylation of a 91-kD DNA binding protein. Science 258:1808-1812

Schindler C, Shuai K, Prezioso VR, Darnell JE Jr (1992b) Interferon-dependent tyrosine phosphorylation of a latent cytoplasmic transcription factor. Science 257:809-813

Sheahan T, Morrison TE, Funkhouser W, Uematsu S, Akira S, Baric RS, Heise MT (2008) MyD88 is required for protection from lethal infection with a mouse-adapted SARS-CoV. PLoS Pathog E1000240 
Shuai K, Stark GR, Kerr IM, Darnell JE Jr (1993) A single phosphotyrosine residue of Stat91 required for gene activation by interferon-gamma. Science 261:1744-1746

Shuai K, Horvath CM, Huang LH, Qureshi SA, Cowburn D, Darnell JE Jr (1994) Interferon activation of the transcription factor Stat91 involves dimerization through SH2-phosphotyrosyl peptide interactions. Cell 76:821-828

Silva AM, Whitmore M, Xu Z, Jiang Z, Li X, Williams BR (2004) Protein kinase R (PKR) interacts with and activates mitogen-activated protein kinase kinase 6 (MKK6) in response to double-stranded RNA stimulation. J Biol Chem 279:37670-37676

Smith JA, Poteet-Smith CE, Malarkey K, Sturgill TW (1999) Identification of an extracellular signal-regulated kinase (ERK) docking site in ribosomal S6 kinase, a sequence critical for activation by ERK in vivo. J Biol Chem 274:2893-2898

Spaziani A, Alisi A, Sanna D, Balsano C (2006) Role of p38 MAPK and RNA-dependent protein kinase (PKR) in Hepatitis C virus core-dependent nuclear delocalization of Cyclin B1. J Biol Chem 281:10983-10989

Su HL, Liao CL, Lin YL (2002) Japanese encephalitis virus infection initiates endoplasmic reticulum stress and an unfolded protein response. J Virol 76:4162-4171

Surjit M, Liu B, Jameel S, Chow VTK, Lal SK (2004) The SARS coronavirus nucleocapsid (N) protein induces actin reorganization and apoptosis in COS-1 cells. Biochem J 383:13-18

Surjit M, Kumar R, Mishra RN, Reddy MK, Chow VT, Lal SK (2005) The severe acute respiratory syndrome coronavirus nucleocapsid protein is phosphorylated and localizes in the cytoplasm by 14-3-3-mediated translocation. J Virol 79:11476-11486

Surjit M, Liu B, Chow VT, Lal SK (2006) The nucleocapsid protein of severe acute respiratory syndrome-coronavirus inhibits the activity of cyclin-cyclin-dependent kinase complex and blocks S phase progression in mammalian cells. J Biol Chem 281:10669-10681

Tan Y, Rouse J, Zhang A, Cariati S, Cohen P, Comb MJ (1996) FGF and stress regulate CREB and ATF-1 via a pathway involving p38 MAP kinase and MAPKAP kinase-2. EMBO J 15:46294642

Tan YX, Tan TH, Lee MJ, Tham PY, Gunalan V, Druce J, Birch C, Catton M, Fu NY, Yu VC, Tan YJ (2007) Induction of apoptosis by the severe acute respiratory syndrome coronavirus $7 \mathrm{a}$ protein is dependent on its interaction with the Bcl-XL protein. J Virol 81:6346-6355

Thiel V, Ivanov KA, Putics A, Hertzig T, Schelle B, Bayer S, Weissbrich B, Snijder EJ, Rabenau $\mathrm{H}$, Doerr HW et al (2003) Mechanisms and enzymes involved in SARS coronavirus genome expression. J Gen Virol 84:2305-2315

Toker A (2000) Protein kinases as mediators of phosphoinositide 3-kinase signaling. Mol Pharmacol 57:652-658

Tsang KW, Ho PL, Ooi GC, Yee WK, Wang T, Chan-Yeung M, Lam WK, Seto WH, Yam LY, Cheung TM et al (2003) A cluster of cases of severe acute respiratory syndrome in Hong Kong. N Engl J Med 348:1977-1985

von Knethen A, Lotero A, Brune B (1998) Etoposide and cisplatin induced apoptosis in activated RAW 264.7 macrophages is attenuated by cAMP-induced gene expression. Oncogene 17: 387-394

Wang XZ, Lawson B, Brewer JW, Zinszner H, Sanjay A, Mi LJ, Boorstein R, Kreibich G, Hendershot LM, Ron D (1996) Signals from the stressed endoplasmic reticulum induce C/ EBP-homologous protein (CHOP/GADD153). Mol Cell Biol 16:4273-4280

Waye YM, Law WP, Wong CH, C Au T, Chuck CP, Kong SK, S Chan P, To KF, I Lo A, W Chan J, Suen YK, Edwin Chan HY, Fung KP, Y Sung J, Dennis Lo YM, W Tsui S. (2005) The 3a protein of SARS-coronavirus induces apoptosis in Vero E6 cells. Conf Proc IEEE Eng Med Biol Soc 7:7482-7485

Wei L, Sun S, Xu CH, Zhang J, Xu Y, Zhu H, Peh SC, Korteweg C, McNutt MA, Gu J (2007) Pathology of the thyroid in severe acute respiratory syndrome. Hum Pathol 38:95-102

Welch H, Eguinoa A, Stephens LR, Hawkins PT PT (1998) Protein kinase B and rac are activated in parallel within a phosphatidylinositide $3 \mathrm{OH}$-kinase-controlled signaling pathway. J Biol Chem 273:11248-11256 
Wong SL, Chen Y, Chan CM, Chan CS, Chan PK, Chui YL, Fung KP, Waye MM, Tsui SK, Chan HY (2005) In vivo functional characterization of the SARS-Coronavirus 3a protein in Drosophila. Biochem Biophys Res Commun 337:720-729

Wu CH, Yeh SH, Tsay YG, Shieh YH, Kao CL, Chen YS, Wang SH, Kuo TJ, Chen DS, Chen PJ (2009) Glycogen synthase kinase-3 regulates the phosphorylation of severe acute respiratory syndrome coronavirus nucleocapsid protein and viral replication. J Biol Chem 284:5229-5239

Yan H, Xiao G, Zhang J, Hu Y, Yuan F, Cole DK, Zheng C, Gao GF (2004) SARS coronavirus induces apoptosis in Vero E6 cells. J Med Virol 73:323-331

Yan X, Hao Q, Mu Y, Timani KA, Ye L, Zhu Y, Wu J (2006) Nucleocapsid protein of SARS-CoV activates the expression of cyclooxygenase-2 by binding directly to regulatory elements for nuclear factor-kappa B and CCAAT/enhancer binding protein. Int J Biochem Cell Biol 38:1417-1428

Yang Y, Xiong Z, Zhang S, Yan Y, Nguyen J, Ng B, Lu H, Brendese J, Yang F, Wang H, Yang XF (2005) Bcl-xL inhibits T cell apoptosis induced by expression of SARS coronavirus E protein in the absence of growth factors. Biochem J 392:135-143

Ye Z, Wong CK, Li P, Xie Y (2008) A SARS-CoV protein, ORF-6, induces caspase-3 mediated, ER stress and JNK-dependent apoptosis. Biochim Biophys Acta 1780(12):1383-1387

Yount B, Roberts RS, Sims AC, Deming D, Frieman MB, Sparks J, Denison MR, Davis N, Baric RS (2005) Severe acute respiratory syndrome coronavirus group-specific open reading frames encode nonessential functions for replication in cell cultures and mice. J Virol 79:14909_ 14922

Yuan X, Shan Y, Zhao Z, Chen J, Cong Y (2005) G0/G1 arrest and apoptosis induced by SARS$\mathrm{CoV} 3 \mathrm{~b}$ protein in transfected cells. Virol $\mathrm{J} 2: 66$

Yuan X, Wu J, Shan Y, Yao Z, Dong B, Chen B, Zhao Z, Wang S, Chen J, Cong Y (2006) SARS coronavirus 7a protein blocks cell cycle progression at G0/G1 phase via the cyclin D3/pRb pathway. Virology 346:74-85

Yuan X, Yao Z, Wu J, Zhou Y, Shan Y, Dong B, Zhao Z, Hua P, Chen J, Cong Y (2007) G1 phase cell cycle arrest induced by SARS-CoV 3a protein via the cyclin D3/pRb pathway. Am J Respir Cell Mol Biol 37:9-19

Zhang L, Wei L, Jiang D, Wang J, Cong X, Fei R (2007) SARS-CoV nucleocapsid protein induced apoptosis of COS-1 mediated by the mitochondrial pathway. Artif Cells Blood Substit Immobil Biotechnol 35:237-253

Zhao G, Shi SQ, Yang Y, Peng JP (2006) M and N proteins of SARS coronavirus induce apoptosis in HPF cells. Cell Biol Toxicol 22:313-322

Zhao X, Nicholls JM, Chen YG (2008) Severe acute respiratory syndrome-associated coronavirus nucleocapsid protein interacts with $\mathrm{Smad} 3$ and modulates transforming growth factor-beta signaling. J Biol Chem 283:3272-3280 